УДК $78.01+783.2$

\title{
С. Осадчая
}

\section{ЭВОЛЮЦИОННАЯ РОЛЬ «ПЕРЕХОДНЫХ ЭПОХ» В РАЗВИТИИ ПРАВОСЛАВНОГО БОГОСЛУЖЕБНОГО ПЕНИЯ: ОТ АВТОРИТЕТА ТРАДИЦИИ К ФЕНОМЕНУ АВТОРСТВА}

Статья посвящена рассмотрению эволюционной роли «переходных» эпох в развитии православного богослужебного пения - рубежи $X I X-X X$ и XX-XXI вв. Обращается внимание на то, что именно певческая, музыкальная сторона оказалась способна наиболее ясно выявить и отобразить психологические процессы, происходящие в социуме. В данном контексте особенно важным становится рассмотрение феномена авторства и его соотношение с традицией.

Ключевые слова: православное богослужебное пение, богослужебнопевческая система, духовная музыка, церковная традиция, автор .

В изучении богослужебно-певческой системы наиболее неоднозначными, а потому и наиболее интересными представляются два периода, а именно рубежи XIX-XX и XX-XXI веков, объединенные тенденцией переосмысления и переоценки многих социальных, в том числе в качестве ведущих, религиозных культурных ценностей, а также выведением взаимоотношений культурного и религиозного сознания на качественно новый уровень. В силу многих исторических обстоятельств на рубеже XIX-XX веков доминировали признаки обмирщения культуры, секуляризации общества; на рубеже $\mathrm{XX}$-XXI проблема оппозиции светского, мирского и церковного, храмового проявляется еще более остро, но, скорее, в обратном направлении. Сегодня можно говорить о тенденции омассовления религиозных ценностей, при которой дискуссии на религиозные темы заняли прочное место в функционировании масс-медийных средств организации информационного пространства современного общества, что активно проявляется во всевозможных публикациях и телевизионных передачах. Это, безусловно, очень важный и значительный поворот в истории отечественной культуры, но при всем его положительном значении необходимо сказать и об иной его стороне. При обращении к храмовой тематике, тем более - к каноническим богослужебным текстам, как к основе современных музыкальных композиций, часто выявляется весьма слабая осведомленность авторов (композиторов) об истинном содержании избранного текста или литургической темы, об их обязательных формальных признаках, о

(C) Осадчая С., 2014 
функциональном назначении православной службы. Подобная ситуация также часто возникает и в средствах массовой информации, например, на телевидении - как таком коллективном виде творчества, результат которого зависит от согласованных усилий немалого количества людей - сценариста, режиссера, оператора (основных создателей передачи), от уровня работы звукорежиссера и даже от инженерного обслуживания монтажа. В применении к передаче православного отношения к миру и человеку, отношение к Церкви и причастность к ней тех или иных участников творческого процесса, не подменяя их светских профессиональных качеств, является решающим фактором творческой удачи или неудачи; хотя важна и обратная зависимость: никакое личное благочестие не может заменить и не заменяет знания, таланта, профессионального опыта.

В связи с популяризацией религиозной и даже богослужебной тематики, демонстрирующей зачастую недостаточно профессиональный подход, возможна утрата символического содержания - символической «теплоты сплачивающей тайны» (С. Аверинцев), которая должна быть неотъемлемой частью всего, что связано с богослужением; в этом случае неизбежным становится размывание границы между храмовым и светским творчеством. Данный вопрос чрезвычайно важен для понимания современного положения православной культуры в мире. Попытка же ответить на него возможна лишь при внимательном анализе взаимоотношений церковной и внецерковной, светской форм культуры, от начала христианства и до наших дней.

Сегодня тема православной культуры, в том числе и певческой, стала настолько актуальной (даже с некоторыми элементами «ментальной агрессии»), что породила необычайную пестроту и эклектичность в оценках православных музыкальных артефактов. Справедливости ради надо сказать, что певческая культура Православной церкви в начале XX в. вызывала не меньшую полемику. Но также следует отметить, что богослужебное пение начала XX века и конца $\mathrm{XX}$ века - заметно отличающиеся культурные феномены, хотя и связанные общностью музыкально-интонационных истоков, жанровой «памятью» певческой традиции.

Если в начале XX века духовную певческую культуру характеризовало стремление возродить самобытную певческую культуру предков, обрести утраченные древние мелодические пласты, то конец XX века пытается «реанимировать» не только давно ушедшее прошлое, но и совсем недавний отрезок времени, поднявший православную куль- 
туру на качественно новый профессиональный уровень. Если тогда, то есть в начале XX века, как выразился А. Гречанинов, «пробивали брешь», то теперь, в конце XX - начале XXI века, брешь заделывали, пытаясь восстановить то, что было утрачено, но одновременно с этим пытаясь создавать и новое.

Подобная двойственность задач современной духовно-певческой культуры привела к рождению уникального хронотопического синтеза, принимающего значение стилевого. Ранее, в историческом развертывании, процессы эволюции богослужебного пения протекали в линейном порядке, то есть период господства одного певческого стиля сменялся другим, вытесняя предыдущий практически полностью, причем границы, стыки этих преобразований в богослужебном пении представлялись весьма примечательным явлением: разрыв между уходящим и зарождающимся стилями был настолько велик, что трудно было предположить данную возможность стилевой смены в процессе эволюции богослужебной певческой практики.

Иными словами, такой стилевой сдвиг представлялся не закономерностью эволюции, а, скорее, результатом некоего «взрыва», полной реформации коллективного религиозного сознания, и именно певческая, музыкальная сторона оказалась способна наиболее ясно выявить и отобразить психологические процессы, происходящие в социуе. Но всякого рода изменения, вносимые непрекращающимся процессом развития личностного сознания, касались исключительно певческой стороны. Уставные каноны, канонические молитвословные тексты практически не претерпевали изменений, что отмечал еще Эгон Велеш, изучая византийскую гимнографию.

Э. Велеш писал о том, что «за исключением нескольких песнопений, гимнов, которые добавились после фиксирования чинопоследования Литургии, духовная поэзия практически не претерпела изменений, но музыкальное развитие не могло быть остановлено. Мы видим, что песнетворцы украшали мелодии, сопровождавшие написанные в строгой форме или в поэтической прозе духовные поэмы. Это происходило до тех пор, пока не возникла необходимость сократить музыкальные тексты, так как во многих случаях украшение музыки сделало невозможным понимание богослужебного текста» [3]. Иными словами, все перемены касались исключительно певческой стороны, оставляя при этом богослужебные тексты неизменными, и если певческая сторона начинала затруднять понимание текста, в нее непременно вносили коррективы. 
Музыкальное творчество (как светское, так и церковное) конца $\mathrm{XX}$ века характеризуется во многом полярными стилевыми явлениями. Так, сегодня мы можем наблюдать одновременное существование всех тех певческих стилей богослужебного пения, которые ранее сменяли друг друга в исторической диахронии. Иными словами, взаимодействие певческих пластов, имеющих ранее горизонтальное выражение, практически полную заменяемость одного другим в процессе эволюции традиции, в современной культуре образует особое симультанное единство, находясь в вертикальном соотношении. Сегодня в церковно-певческой православной практике совместно существуют и активно развиваются такие, казалось бы, несовместимые стилевые явления, как знаменная монодия и многоголосие, к тому же последнее в различных исторических модификациях (партесной, строгой полифонической, свободной, в ее единстве с гомофонногармоническими принципами организации фактуры и в их контаминациях).

Сегодня как монодическое, так и полифоническое пение получают широкий резонанс в культурной жизни: различные фестивали, на которых звучит знаменный роспев, а также научно-практические конференции, посвященные проблемам знаменного распева, перестали быть редкостью. Что наиболее примечательно: сегодня речь идет уже не только о том, каковы проблемы изучения знаменного пения с научной точки зрения (как было это в начале XX века), и не о попытках возродить знаменный распев - этот путь уже в значительной мере пройден, чему свидетельством служат увеличение количества хоровых коллективов, в чьих репертуарах представлен исключительно знаменный распев, и возрастание числа храмов, в которых во время богослужения звучит знаменный распев. Сегодня можно говорить о конкретных практических, учебно-образовательных, «рабочих», в том числе регентских, актуальных проблемах развития знаменного пения.

В современном православном пении сосуществуют различные музыкально-певческие формы, в связи с которыми осуществляются процессы, направленные на решение различных семантических задач. С одной стороны, это клиросные богослужебные песнопения, которые в свою очередь могут быть классифицированы дихотомически.

Bo-nepвыx - это группа пьес, в которых строго соблюдается традиция, сложившаяся в предшествующей церковно-певческой практике. К ним можно отнести те песнопения, которые создавались особо 
«воцерковленными» композиторами, такими как архимандрит Матфей (Мормыль), диакон Сергий Трубачев, епископ Иларион (Алфеев), епископ Ионафан (Елецких) и другие.

Bo-вторых - это группа песнопений, в которой наблюдается заметное обновление средств музыкальной композиции, но с непременным строгим следованием уставному канону. В этих произведениях достаточно ярко выражено авторское «Я», позволяющее композитору донести свое видение и свои представления, сохраняя при этом общую направленность на соблюдение определенных правил жанра. К этой группе можно отнести работы В. Мартынова, по-своему «услышавшего» обиход, композиции Н. Лебедева, М. Скорика, Л. Дычко, Е. Станковича, сочетающие традиционные и нетрадиционные начала в канонических песнопениях, мн. др.

С другой стороны - это духовная музыка, генетически связанная с храмовым, богослужебным пением, но рассчитанная на концертное исполнение, а не на участие в богослужении. Данная область выражена наиболее многочисленно. Следует отметить, что в ней также наблюдается разделение на два магистральных направления. Bo-nервых, это духовные песнопения, в основе которых лежат тексты, связанные с богослужением, с религиозной жизнью, но не являющиеся каноническими. Начало этому направлению было положено еще в конце XIX - начале XX века в творчестве многих видных композиторов, таких как П. Чайковский («Покаянная молитва о Руси»), С. Танеев («Иоанн Дамаскин», «По прочтении псалма»), Н Черепнин («Хождение по мукам Богородицы»), А. Кастальский («Братское поминовение»). Рубеж XX-XXI веков продолжил эту линию, в том числе и в творчестве украинских композиторов, в числе которых уже названные Л. Дычко, М. Скорик, Е. Станкович, В. Каминский.

Bo-вторых, в современной духовной музыке сформировался ряд произведений на канонические тексты, не предназначенных для исполнения в храме. Аналогов этому явлению до сих пор не было, так как использование канонического текста в мирском произведении было запрещено, что строго контролировалось цензурным комитетом Синода. Обходя этот запрет, А. Кастальский первым прибег к переводу богослужебного текста с церковно-славянского языка на русский.

Сегодня можно назвать ряд произведений, в которых сочетается канонический текст с внехрамовой, концертной жанрово-стилевой направленностью, как, например, цикл Л. Панкратова «Три духовных песнопения», в составе которого - «Свете Тихий», «Царице моя 
преблагая», «Верую»; песнопения В. Григоренко «Царю Небесный», «Боже очисти мя грешнаго», И. Соневицкого «Панихида», епископа Илариона (Алфеева) «Страсти по Матфею», а также «Чернобыльская Литургия» епископа Ионафана (Елецких), премьера которой состоялась в Киеве, причем весьма примечательным является существование не только акапельного варианта «Чернобыльской Литургии», но и версии произведения в сопровождении оркестра.

Таким образом, музыкальная культура демонстрирует, с одной стороны, желание восстановить утраченное, «припасть к истокам» религиозной церковной жизни; с другой стороны, никогда еще ранее религиозно-духовная культура в целом, во всех ее проявлениях, не была так обращена к психологии личности. Например, в современной печати появляется литература, в которой поднимаются серьезные богословские вопросы, однако она обращена в большей степени не к духовенству, а к простым мирянам. В музыке - это появление большого пласта произведений на канонические тексты, но направленных на светское исполнение, отражающих опыт общения человека с самим собой, личностные смыслы.

Известно, что на рубеже XIX-XX веков во всех сферах духовной жизни обшества обострилась потребность поиска национальных корней, а идеологами Нового направления в развитии духовной музыки стали С. Смоленский и А. Кастальский, занимающиеся исследованиями в области истории древнерусского певческого искусства, дирижеры и педагоги, авторы обработок древних распевов. В частности, А. Кастальский верил в возрождение национальных основ церковной музыки, а высказанная им мысль о значении старинных знаменных распевов явилась основанием для всей идеологии Нового направления. Взгляд на древние певческие пласты как на основной источник формирования нового типа музыкального мышления позволил А. Кастальскому говорить о необходимости создания полифонической ткани особого типа, насыщенной подголосочным движением.

Изучая произведения древних распевщиков и будучи натурой музыкально-творческой, Кастальский пытался изнутри осмыслить процесс создания тех или иных композиций. Таким образом исследователь благодаря работе с первоисточниками и столь глубокому постижению древнерусского знаменного пения, наблюдая за особенностями строения, мелодики, ритмики древних напевов, пришел к выводу, что западноевропейская гармоническая функциональная основа непригодна для оформления знаменных распевов, поскольку 
мажоро-минорная система вступает в противоречие с их попевочным строением.

Подобные размышления позволяют говорить о возникновении проблемы, касающейся в том числе соотношения традиции и авторства. Явление авторского стиля, равно как и понятие «авторства» в целом, приобретает парадоксальные черты по отношению к музыкальному (певческому) содержанию богослужебного православного чина - центрального элемента и главного «знака» православной культуры - или культуры как православного феномена.

Посредством индивидуально-авторского музыкального языка, выраженного в певческой стороне православной литургии, обозначаются «личностные смыслы» (термин А. Леонтьева), следовательно, уникальное строение личностного сознания. Авторский стиль всегда выражает индивидуализированное психологическое начало, становится «личностной поэтикой», то есть опытом личностной экзистенции, и в таком своем значении оказывается оппозицией соборности - этой важнейшей доминанты коллективного хорового православного сознания, семантической доминанты православной культуры в целом. Эволюция православного пения и обусловленное ею развитие музыкально-литургического стиля в наибольшей степени инициируется авторским стилем, то есть реализацией личностного начала в контексте православной певческой традиции; следовательно, феномен авторского стиля может быть рассмотрен как креативный фактор данной традиции - необходимое условие ее исторической подвижности. Православная певческая традиция обретает автономную музыкально-стилевую систему как единство литургических обиходных и авторских музыкально-языковых установок.

С другой стороны, авторский стиль является симптомом новоевропейского художественного сознания и в этом своем качестве входит в православную певческую культуру; иными словами - это сравнительно поздний исторический феномен, развивающийся на основе коренной, устоявшейся общинной традиции, в подчинении требованиям коллективного богослужения, прежде всего, соборности - как главной установки православного сознания.

Хотя о проблеме соборности как о доминирующей установке православного сознания уже упоминалось на страницах работы, следует напомнить, что соборность, понимаемая как обеспеченное духовной общностью движение к истине, возможна лишь в Церкви. Однако общинное сознание, даже в канонизированной религиозно-культовой 
области, не является неизменной величиной, приобретает особые черты в каждую из тех конкретных исторических эпох, с которыми связано его бытие, а значит - имеет свои признаки культурно-исторической обусловленности, в том числе свои принципы зависимости от уровня и типа личностной психологии. Категория соборности также не является «застывшей» смысловой структурой; потому особую актуальность приобретает рассмотрение ее исторической динамики - применительно к изменениям в «образе человека», в том числе в образе «человека литургического».

Византийский вариант христианства, принесенный монахами, художниками и певчими Византии, вступил во взаимодействие со славянским язычеством и особенностями славянского характера. Это взаимовлияние и взаимопроникновение порождают такой уникальный культурный феномен, как церковная и церковно-певческая культура Православной церкви. Вслед за византийским православием православие Киевской Руси сочетает склонность к философскому рассмотрению религии с высокой оценкой важности обряда. Как отмечал П. Флоренский, «вместе с разработанной теософией, где выясняются в философских терминах отношения между Лицами Пресвятой Троицы, между естествами в Богочеловеке, понятия Церкви, спасения, бессмертия и т. п., в восточной религиозности не меньшее значение имеет глубокое уважение к обряду, так что исполнение его ставится рядом и даже выше исполнения нравственных заветов» [2, c. 468]. Иными словами, соблюдение в неприкосновенности и во всех подробностях обряда становится одной из главных забот церкви. Это пристальное внимание распространяется и на певческую сторону обряда. Таким образом, отличительная черта православного отношения к Церкви - это перевес участия в культе и обряде над любыми нравоучительными действиями: непосредственное участие в церковной жизни гораздо важнее сухого изучения богослужения по книгам. В свою очередь, культ и православный обряд необычайно внимательны к наиболее важным моментам жизни человека - «рождение, смерть, брак происходят пред лицом Бога и благословляются таинствами и богослужениями» [2, с. 478].

Но создатели певческой стороны богослужения должны были идти путем церковности, жизни в культе, иными словами, их путь представлял собой, в первую очередь, жизнь внутри церковного обряда, жизнь «человека литургического». Именно на эту особенность указывал С. Аверинцев, когда противопоставлял взгляды на творче- 
ство со стороны «новоевропейского» и средневекового художников. Он говорил, что «новоевропейский художник видит в себе «творца» и понимает свою работу как «творчество». Между тем ни античный, ни средневековый художник этого делать не могли, хотя по совершенно противоположным причинам для первого не существовало библейской концепции Божественного творческого акта, приводящего вещи от небытия к бытию, а для второго, напротив, эта концепция обладала безусловной конкретностью, не оставлявшей места для метафорических переосмыслений» [1, с. 407].

Следует особенно подчеркнуть, что под каноном, канонической формой П. Флоренский всегда подразумевает установленный церковью и в церкви порядок человеческих отношений с миром, то есть миропорядок. Структура православной службы, собственно чинопоследование, пространство и время, то есть - темпорально-спатиальные свойства литургии, являются строго канонизированными и не допускают авторского вмешательства, но отношение к произносимому (пропеваемому) словесному тексту - к способу музыкального интонирования - может быть индивидуально интерпретируемым.

По отношению к словесному материалу песнопения возможны два направления авторской свободы - индивидуального стилевого выбора, конечно, в известных канонических стилистических границах: трактовка мелодической горизонтали, то есть временного экспрессивно-интонационного развертывания канонического текста (например, в произведениях А. Кастальского предельно мелодизированы все хоровые партии при соблюдении единства характера звучания и типа движения хоровых голосов); формирование фактурно-гармонической вертикали как специфически-музыкального способа организации пространства (например, в красочных, развернутых композициях А. Гречанинова, С. Рахманинова, П. Чеснокова используются разнообразные divisi, динамические эффекты, сложные многозвучные гармонии, элементы полифонического изложения, нек. др.).

Общим для данных направлений является ритм - как распределение значащих моментов звучания; ритмическая сторона яснее всего показывает степень авторской свободы и характер художественной эмоции. В этой связи следует говорить об особых путях моделирования эмоций в православном пении, об особом строе «православной музыкальной эмоции» и об ее всегда позитивном оценочном значении.

Даже самые напряженные, «драматургически» кульминационные моменты богослужения принципиально лишены драматизма или па- 
тетики; самые сильные смысловые моменты выражены объективно«Покойно». Православное переживание устремлено к целостности, однородности и постоянству духовного познания, поднимаясь над эпизодичностью, фрагментарностью, скоротечностью душевных проявлений личности. Отсюда - особая семантика музыкальных средств, особая типология психологических состояний (личностных эмоций) в православной музыкальной культуре, среди которых ведущим следует признать то душевное упокоение (снятие душевного смятения, трезвение и очищение в Духе), которое соединено с уподоблением и является необходимой его стороной. (В этом, на наш взгляд, и выражается катартическая установка православного сознания. Кроме того, слова «покой», «подобие», «собор - соборность соборование» обладают в русском языке особенно глубинной семантикой и широким ассоциативным полем.)

Авторски-индивидуальные стилевые особенности православного пения подчеркивают значение соборности как «естественного» существования традиции. Уподобление-упокоение, то есть ведущая катартическая установка православного сознания и его певческого выражения, является результатом соборного единения. В связи с этим новую актуальность приобретает введенное Д. Лихачевым понятие о таком стилевом направлении в древнерусской литературе, как «умиротворенный психологический стиль»; данный стилевой модус Лихачев рассматривает в связи с подчинением индивидуального чувства «мировому» переживанию, то есть чувству «всем миром», вместе со всей общиной; растворение индивидуально-личностного в коллективном сознании и есть умиротворенность - не случайно в православной традиции предпочтение отдается коллективной молитве.

Таким образом, православная традиция формирует особые требования к смысловой структуре личностного сознания и его катартическим свойствам. Символика православной музыки также приобретает иной, по сравнению с художественной, характер; для нее типично стремление к полной нераздельности знака и значения, формы и смысла, тогда как автономная художественная символика увеличивает дистанцию между ними, открывает безграничность значений для данной знаковой формы и вариабельность знаковой формы для данного значения.

Литургические символы в музыке возникают благодаря закрепленности определенного способа, приема озвучивания за определенным молитвенным текстом, устойчивости его места в службе в целом. Таким образом, молитвословный уровень выступает как фактор семан- 
тической стабильности - закрепленности смыслового значения за конкретным музыкальным элементом, что и позволяет последнему входить в «генерализованную» музыкальную интонацию. Как и словесный, генерализованный музыкальный знак складывается из простых элементов музыкальной речи.

Смысловая структура музыкального символа многослойна и рассчитана на активную работу исполнительского и слушательского восприятия. «Причем эти смыслы не только в равной мере присутствуют во внутренней структуре произведения, но и переливаются один в другой: так, в образе космического равновесия можно, в свою очередь, увидеть только знак для нравственно-социальной человеческой гармонии, но возможно поменять значащее и означаемое местами, так что мысль будет идти от человеческого ко вселенскому согласию» [1, с. 155]. Смысл символа существует не как данность, а как некая «заданность». Символ невозможно разъяснить какой-либо простой логической формулой, его можно только пояснить, соотнося «с дальнейшими символическими сцеплениями» (С. Аверинцев), с вновь приобретенными смысловыми значениями.

Таким образом, следуя за С. Аверинцевым, мы можем заключить, что каноническое композиторское сознание искало и находило в богослужебных книгах, в церковном Писании и церковном Предании «регламентирующие первообразы всякого человеческого состояния, сана и «чина» $[1$, с. 408]. Эти источники становились своего рода «символическим зеркалом», в котором каждый художник должен был увидеть и осознать себя.

Следовательно, в целом, задача автора, входящего в символическое русло православной традиции, принципиально отличается от светской композиторской и, прежде всего, состоит в том, чтобы привлечь необходимую символическую форму для известного устойчивого и неизменного религиозного смысла, таким образом утвердить вечное в аспекте временного, духовную усию - путем личностной ипостаси.

\section{СПИСОК ЛИТЕРАТУРЫ}

1. Аверинцев С. Поэтика ранневизантийской литературы / С. Аверинцев. - СПб. : Азбука-классика, 2004. - 408 с.

2. Флоренский П. Православие / П. Флоренский // Христианство и культура. - М. : Аст, 2001. - С. 465-490.

3. Wellesz E. A histori of Byzantine music and himnografhy / E. Wellesz. - Oxford : At the Clarendon press, 1949. $-494 \mathrm{p}$. 
Осадиа С. Еволюційна роль «перехідних епох» у розвитку православного богослужбового співу: від авторитета традиції до феномена авторства. Стаття присвячена розгляду еволюційної ролі «перехідних» епох у розвитку православного співу, а саме рубежам XIX-XX і XX-XXI ст. Звертається увага на те, що саме співоча, музична сторона виявилася здатною найбільш ясно виявити і відобразити психологічні процеси, що відбуваються в соціумі. У даному контексті особливо важливим стає розгляд феномена авторства і його співвідношення з традицією.

Ключові слова: православний богослужбовий спів, богослужбово-співоча система, духовна музика, церковна традиція, автор.

Osadchaya S. The evolutionary role of «transition age» for the Orthodox liturgical singing: from the authority of tradition to the phenomenon authorship. The article considers the evolutionary role of «transitional» era in the development of Orthodox liturgical singing - the XIX-XX and XX-XXI centuries. Draws attention to the fact that it is singing, musical side was able to most clearly identify and display the psychological processes taking place in society. In this context it is particularly important is the consideration of the phenomenon of authorship and its relationship to tradition.

Keywords: Orthodox liturgical singing, liturgical singing-system, sacred music, church tradition, the author.

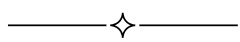

UDK $78.01+783.2$

\section{S. Osadchaya}

\section{EVOLUTIONARY ROLE OF "TRANSITION AGES" IN THE DEVELOPMENT OF THE ORTHODOX LITURGICAL SINGING: FROM AUTHORITY OF A TRADITION TO THE PHENOMENON OF AUTHORSHIP}

The Article considers the evolutionary role of "transitional" era in the development of the Orthodox liturgical singing - the XIX-XX and XX-XXI centuries. Attention is drawn to the fact that it was singing, musical side was able to more clearly identify and reflect the psychological processes that take place in the society. In this context, consideration of the phenomenon of authorship and its relationship to tradition becomes particular important.

Keywords: Orthodox liturgical singing, liturgical singing-system, sacred music, church tradition, and author. 